\begin{tabular}{|c|l|}
\hline Title & Correlation between kinetics and chemical bonding state of catalyst surface in catalyzed magnesium hydride \\
\hline Author(s) & $\begin{array}{l}\text { Ma, Tao; Isobe, Shigehito; Morita, Eri; Wang, Y ongming; Hashimoto, Naoy uki; Ohnuki, Somei; Kimura, Toru; } \\
\text { Ichikawa, Takayuki; Kojima, Y oshitsugu }\end{array}$ \\
\hline Citation & $\begin{array}{l}\text { International Journal of Hydrogen Energy, 36(19), 12319-12323 } \\
\text { https://doi.org/10.1016/.ijhydene.2011.07.011 }\end{array}$ \\
\hline Issue Date & 2011-09 \\
\hline Doc URL & http://hdl.handle.net/2115/47469 \\
\hline Type & article (author version) \\
\hline File Information & IJHE36-19_12319-12323.pdf \\
\hline
\end{tabular}

Instructions for use 


\title{
Correlation between Kinetics and Chemical Bonding State of Catalyst Surface in Catalyzed Magnesium Hydride
}

Tao $\mathrm{Ma}^{\mathrm{a}}$, Shigehito Isobe ${ }^{* \mathrm{a}}$, Eri Morita ${ }^{\mathrm{a}}$, Yongming Wang ${ }^{\mathrm{a}}$, Naoyuki Hashimoto ${ }^{\mathrm{a}}$, Somei Ohnuki ${ }^{a}$, Toru Kimura ${ }^{b}$, Takayuki Ichikawa ${ }^{b}$, Yoshitsugu Kojima ${ }^{b}$

${ }^{\text {a }}$ Graduate School of Engineering, Hokkaido University, N-13, W-8, Sapporo

060-8278, Japan

${ }^{\mathrm{b}}$ Institute for Advanced Materials Research, Hiroshima University, Japan

\begin{abstract}
We reported on the hydrogen desorption properties, microstructure, kinetics, and chemical bonding state of catalyst surface for composites of $\mathrm{MgH}_{2}$ and $1 \mathrm{~mol} \% \mathrm{Nb}_{2} \mathrm{O}_{5}$ ball-milled for $0.02 \mathrm{~h}, 0.2 \mathrm{~h}, 2 \mathrm{~h}, 20 \mathrm{~h}$ under $1 \mathrm{MPa} \mathrm{H}_{2}$ atmosphere, as well as hand-mixed (HM) one. Hydrogen desorption properties were significantly improved by ball-milling with $\mathrm{Nb}_{2} \mathrm{O}_{5}$. Then, we estimated by Kissinger Method the activation energy $\left(E_{a}\right)$ of hydrogen desorption reaction that decreased with the increase of ball-milling time. Especially, $E_{a}$ of the sample ball-milled for $0.2 \mathrm{~h}$ was drastically

\footnotetext{
${ }^{*}$ Corresponding author Tel/FAX: +81-11-706-6772

E-mail address: isobe@eng.hokudai.ac.jp (S. Isobe).
} 
decreased, compared with that of the sample ball-milled for $0.02 \mathrm{~h}$. TEM observations revealed that the distribution of $\mathrm{Nb}_{2} \mathrm{O}_{5}$ in $\mathrm{MgH}_{2}$ was gradually improved during ball-milling. On the other hand, we confirmed by XPS that in the sample ball-milled for $0.2 \mathrm{~h}, \mathrm{Nb}_{2} \mathrm{O}_{5-\mathrm{x}}$ phase(s) existed at least on the surface. It can be suggested that these deoxidized $\mathrm{Nb}_{2} \mathrm{O}_{5 \text {-x }}$ phases eventually decrease $E_{a}$ as substantial catalyst rather than $\mathrm{Nb}_{2} \mathrm{O}_{5}$ itself.

Keywords: Hydrogen Storage Materials; $\mathrm{MgH}_{2}$; Oxide Catalyst; XPS; TEM

\section{Introduction}

Many kinds of hydrogen absorbing materials have been studied in order to store hydrogen, such as sodium alanates [1],[2], metal nitrides [3],[4], as well as $\mathrm{MgH}_{2}$ [5],[6], which is one candidate because of its high hydrogen capacity (7.6 mass\%). However, the absorption and desorption reaction of $\mathrm{Mg} / \mathrm{MgH}_{2}$ itself is too slow. Recently, scientists found out that the composite of $\mathrm{MgH}_{2}$ and transition metal compounds prepared by ball-milling showed improved kinetics for both hydrogen absorption and desorption [7]-[11], which can be seen as a good indicator for practical application. Barkhordarian et al. reported that the $\mathrm{Nb}_{2} \mathrm{O}_{5}$ had a superior catalytic 
effect for absorption and desorption, compared to other metal oxide catalysts. The magnesium hydride catalyzed with $0.5 \mathrm{~mol} \% \mathrm{Nb}_{2} \mathrm{O}_{5}$, which was ball-milled for $100 \mathrm{~h}$, finished full desorption within 90 seconds under vacuum conditions at $300{ }^{\circ} \mathrm{C}$. The desorbed products could also absorb roughly 7 mass $\%$ of hydrogen within 60 seconds under 8.4 bar of hydrogen at $300{ }^{\circ} \mathrm{C}$ [10]. Hanada et al. reported that the desorbed composite, $\mathrm{MgH}_{2}$ with $1 \mathrm{~mol} \% \mathrm{Nb}_{2} \mathrm{O}_{5}$ milled for $20 \mathrm{~h}$, was able to absorb 4.5 mass $\%$ of hydrogen under lower pressure than 1.0 MPa within 15 seconds even at room temperature [11]. However, the mechanism of this significant catalytic effect has not been clarified yet. Hanada et al. observed the ball-milled $\mathrm{MgH}_{2}-\mathrm{Nb}_{2} \mathrm{O}_{5}$ mixture by the Transmission Electron Microscope (TEM) and found that the additive particles were homogeneously distributed in $\mathrm{MgH}_{2}$ particles within nanometer scale, thus leading to the fast kinetics [12]. Additionally, they performed X-ray absorption spectroscopy for investigating the valence of metal oxide additives such as $\mathrm{Nb}_{2} \mathrm{O}_{5}$ and $\mathrm{V}_{2} \mathrm{O}_{5}$. The results showed that the metal oxide had been reduced by ball-milling with $\mathrm{MgH}_{2}$ for 20 h. Therefore, they suggested that the improvement of hydrogen sorption was caused by the catalytic effect of reduced metal oxides [13]. Meanwhile, Porcu et al. confirmed via High Resolution TEM that in the $\mathrm{MgH}_{2}-\mathrm{Nb}_{2} \mathrm{O}_{5}$ ball-milled composite $\mathrm{MgNb}_{2} \mathrm{O}_{3.67}$ was present, which may elaborate on the improved kinetics [14]. With respect to the chemical bonding state of niobium, both results indicated that the 
reduced niobium oxide existed in the sample after milling with $\mathrm{MgH}_{2}$. However, few works have been done to directly clarify the correlation between the kinetics and the reduced catalyst. The exact mechanism of how the reduced oxides affect the kinetics of reaction should be investigated further in order to develop catalytic effect in hydrogen storage materials, not only in $\mathrm{MgH}_{2}$. In this work, we have investigated the kinetics of desorption, the morphology and the chemical state on the surface of the catalyst in $\mathrm{MgH}_{2}-\mathrm{Nb}_{2} \mathrm{O}_{5}$ composites ball-milled for varied time. Especially, we have tried to trace the change of chemical bonding states of catalyst surface by X-ray photoelectron spectroscopy (XPS) under the consideration that the state of catalyst surface is the most important factor affecting the kinetics of desorption.

\section{Experimental Procedures}

$\mathrm{MgH}_{2}$ powder was purchased from Alfa Aesar with a purity of $98 \% . \mathrm{Nb}_{2} \mathrm{O}_{5}$ powder with the purity of $99.99 \%$ was also purchased from the Kojundo chemical Laboratory, with a size of $\sim 1 \mu \mathrm{m}$. Ball-milling was performed using a Fritsch P7 device. The samples, mixtures of $300 \mathrm{mg} \mathrm{MgH}_{2}$ and $1 \mathrm{~mol} \% \mathrm{Nb}_{2} \mathrm{O}_{5}$, were ball-milled with 20 steel balls $(7 \mathrm{~mm}$ in diameter) for $0.02 \mathrm{~h}, 0.2 \mathrm{~h}, 2 \mathrm{~h}$ and $20 \mathrm{~h}$. The ball-to-powder ratio was 100:1. The hydrogen pressure inside the milling spot was 1 $\mathrm{MPa}$ and the rotating speed was $400 \mathrm{rpm}$ during milling. Also, hand-mixed (HM) 
sample with the same composition was prepared by agate mortar. All the samples were treated without exposure to air, because of the instability of $\mathrm{MgH}_{2}$. The hydrogen desorption properties were examined by thermal desorption spectroscopy (TDS) with several rates from 1 to $20^{\circ} \mathrm{C} / \mathrm{min}$ under a highly pure helium flow. X-ray diffraction (XRD) was performed by using JEOL JDX-3500 powder diffractometer with $\mathrm{Cu} \mathrm{K}_{\alpha}$ radiation. The samples were observed by $200 \mathrm{kV}$ TEM (JEOL JEM-2010). XPS was carried out using a JPS-90MX photoelectron spectrometer with $\mathrm{Mg} \mathrm{K}_{\alpha}$ radiation. The energy scale of the spectrometer is calibrated by setting oxygen $(\mathrm{O} 1 \mathrm{~s})$ peak to $532 \mathrm{eV}$. The spectra were smoothed and subtracted the background according to the Shirley method. Peak separation was performed using Gaussian-Lorrentz routines with the ratio of 0.8 . The area ratio was fixed to $2 / 3$ due to spin-orbit coupling and the distance $2.7 \mathrm{eV}$ between $\mathrm{Nb} 3 \mathrm{~d}_{3 / 2}$ and $\mathrm{Nb} 3 \mathrm{~d}_{5 / 2}$ peaks.

\section{Results and Discussion}

Figure 1 shows the profiles of TDS of hydrogen for the composites with a heating rate of $5{ }^{\circ} \mathrm{C} / \mathrm{min}$. It can be seen that as the ball-milling time increased, the peak temperatures of hydrogen desorption are decreasing, meaning the catalytic effect was gradually activated and improved during ball-milling. By measuring TDS at different heating rate, the activation energy $\left(E_{a}\right)$ of desorption was calculated by Kissinger 
Method [15], according to the following equation;

$$
\ln \left(\beta / T_{P}^{2}\right)=-E_{a} / R T_{p}+\ln \left(k_{0} R / E_{a}\right)
$$

where $\beta$ is the heating rate, $T_{P}$ indicates the peak temperatures of desorption, $R$ is the gas constant and $k_{0}$ is the frequency factor. If plotting $\ln \left(\beta / T_{P}{ }^{2}\right)$ as the function of the inverse of $T_{P}$, straight lines can be obtained, namely the Kissinger plot. From the slope of the straight lines $E_{a}$ for the HM sample and those ball-milled for $0.02 \mathrm{~h}, 0.2 \mathrm{~h}$, $2 \mathrm{~h}$ and $20 \mathrm{~h}$ was estimated to be $147 \mathrm{~kJ} / \mathrm{molH}_{2}, 138 \mathrm{~kJ} / \mathrm{molH}_{2}, 82 \mathrm{~kJ} / \mathrm{molH}_{2}, 70$ $\mathrm{kJ} / \mathrm{molH}_{2}$ and $63 \mathrm{~kJ} / \mathrm{molH}_{2}$, respectively. The correlation between $E_{a}$ and ball-milling time was shown in Fig 2. It can be seen that $E_{a}$ decreases with the increase of ball-milling time. Especially between the samples ball-milled for $0.02 \mathrm{~h}$ and $0.2 \mathrm{~h}$, a large reduction of $E_{a}\left(\sim 56 \mathrm{~kJ} / \mathrm{molH}_{2}\right)$ has been reached, which is worth discussion. This indicates that some changes were brought by ball-milling and hence improved the catalytic effect of $\mathrm{Nb}_{2} \mathrm{O}_{5}$. To understand the mechanism of the catalytic effect, these changes should be investigated.

XRD patterns of the samples were obtained to evaluate the crystalline information, as shown in Fig 3. The width of the peaks widened and the intensity drastically decreased when the samples were milled for a long time. It indicates that the grain size of both $\mathrm{MgH}_{2}$ and $\mathrm{Nb}_{2} \mathrm{O}_{5}$ becomes smaller during ball-milling. This refinement of grains may suggest the decrease of size for both $\mathrm{MgH}_{2}$ and $\mathrm{Nb}_{2} \mathrm{O}_{5}$ particles, leading to 
a better distribution of catalyst in the samples. TEM observation provides evidence for the inference above. In the bright field images shown in Fig 4a-4e (all of them were in the same scale), two kinds of particles could be distinguished by different contrast. The selected area diffraction was applied for both of them (see area A and B in Fig 4b). In Fig $4 \mathrm{~g}$ the spots with streak (obtained from area $\mathrm{B}$ ) are recognized as $\mathrm{Nb}_{2} \mathrm{O}_{5}$, while in Fig4f the Debye rings (obtained from area $\mathrm{A}$ ) are confirmed as $\mathrm{Mg}$ and $\mathrm{MgO}$. Therefore, in the bright field images the particles with very dark contrast should be $\mathrm{Nb}_{2} \mathrm{O}_{5}$ while the others are $\mathrm{Mg}$ related phases. $\mathrm{MgH}_{2}$ was not found because of the fast decomposition under the electron beam, as discussed in other papers [12],[14]. When comparing the images, it can be seen that the $\mathrm{Nb}_{2} \mathrm{O}_{5}$ particles were gradually attenuated by ball-milling and a homogeneous distribution was reached in the samples milled for long time. In Fig 4e, e.g., the $\mathrm{Nb}_{2} \mathrm{O}_{5}$ particles imbed homogeneously in the $\mathrm{Mg}$ related phases. The size of the $\mathrm{Nb}_{2} \mathrm{O}_{5}$ particles was estimated to be less than 100 $\mathrm{nm}$. This gradually improved distribution of the catalyst with the refined size should be one factor responsible for the decreased $E_{a}$ and improved kinetics.

However, we noticed that $E_{a}$ decreased not gradually but in fact drastically when the sample was milled for $0.2 \mathrm{~h}$. Thus there should be other factors that affect the kinetics more essentially. Under this consideration, XPS measurements were carried out for further investigation. The niobium (Nb3d) spectra were drawn in Fig 5 after 
calibration. A decrease of the Nb3d signal with ball-milling can be seen, reasserting the results from elsewhere [16],[17]. The decrease could be explained as the milled $\mathrm{MgH}_{2}$ particles covered the surface of $\mathrm{Nb}_{2} \mathrm{O}_{5}$, preventing the detector from getting enough signal from inside. It can be seen that the position of the $\mathrm{Nb3d}$ peaks detected almost remain the same, even after the sample was milled for a substantial period. However, the obviously widened peaks were obtained in the sample milled for $0.2 \mathrm{~h}$. Further separation of those peaks shown in the inserted graph resulted in a coexistence of 4 peaks. There are two peaks at $210.2 \mathrm{eV}$ and $207.5 \mathrm{eV}$, which are corresponding to

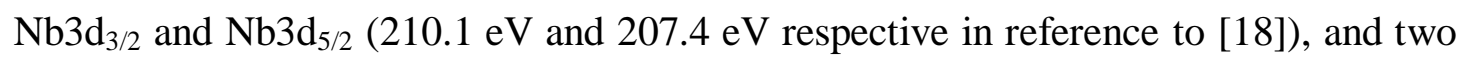
new peaks appearing to the right. Though the signal is not strong enough to identify the exact phase for the new peaks, the shift to lower energy infers that the chemical state of $\mathrm{Nb}$ has changed at least on the surface of the sample. A certain or a complication of $\mathrm{Nb}_{2} \mathrm{O}_{5-\mathrm{x}}$ phase(s) appeared in the sample milled for $0.2 \mathrm{~h}$. The deoxidized $\mathrm{Nb}_{2} \mathrm{O}_{5-\mathrm{x}}$ on the surface with the valence of $\mathrm{Nb}$ less than +5 may act as a more effective catalyst that decreases $E_{a}$ and also improve the kinetics of desorption. Here it is also noticed that there was a small shoulder at higher energy side $(\sim 211 \mathrm{eV})$. We considered it as noise because fully oxidized niobium $\left(\mathrm{Nb}_{2} \mathrm{O}_{5}\right)$ should have the Nb3d peak with the highest binding energy. 


\section{Conclusion}

In conclusion, we were able to perform a study on the $\mathrm{HM} \mathrm{MgH}_{2}-\mathrm{Nb}_{2} \mathrm{O}_{5}$ composite as well as those ball-milled for $0.02 \mathrm{~h}, 0.2 \mathrm{~h}, 2 \mathrm{~h}$ and $20 \mathrm{~h}$ under $1 \mathrm{MPa} \mathrm{H}_{2}$ atmosphere. An improved desorption kinetic was reached by ball-milling with $\mathrm{Nb}_{2} \mathrm{O}_{5}$. $E_{a}$ of $\mathrm{HM}, 0.02 \mathrm{~h}, 0.2 \mathrm{~h}, 2 \mathrm{~h}$ and $20 \mathrm{~h}$ samples was estimated to be $147 \mathrm{~kJ} / \mathrm{molH}_{2}, 138$ $\mathrm{kJ} / \mathrm{molH}_{2}, 82 \mathrm{~kJ} / \mathrm{molH}_{2}, 70 \mathrm{~kJ} / \mathrm{molH}_{2}$ and $63 \mathrm{~kJ} / \mathrm{molH}_{2}$, respectively, thus decreasing in accordance with the improved kinetics. XRD and TEM results showed a decrease of particle size for both $\mathrm{MgH}_{2}$ and $\mathrm{Nb}_{2} \mathrm{O}_{5}$ occurred with ball-milling. In the sample milled for $20 \mathrm{~h}$, the $\mathrm{Nb}_{2} \mathrm{O}_{5}$ particles were found imbedding homogeneously in $\mathrm{Mg}$ related phases, with a size of less than $100 \mathrm{~nm}$. The better distribution and the refined size of the $\mathrm{Nb}_{2} \mathrm{O}_{5}$ may be responsible for the decreased $E_{a}$ and improved kinetics for desorption. The chemical state of $\mathrm{Nb}$ was found changed at least on the surface, as evident by XPS results. The peak separation was performed on the XPS spectrum of the sample milled for $0.2 \mathrm{~h}$, indicating that a certain or a complication of deoxidized $\mathrm{Nb}_{2} \mathrm{O}_{5-x}$ phase(s) appeared, which may play an more important role in decreasing $E_{a}$ and improving kinetics for desorption.

\section{Acknowledgement}

This work has been partially supported by NEDO (HYDRSTAR). 


\section{Reference}

[1] Bogdanovic B, Schwickardi M. J. Alloy. Compd. 1997; 1: 253-254.

[2] Luo W, Gross KJ. J. Alloy. Compd. 2004; 385: 224-231.

[3] Ichikawa T, Isobe S, Hanada N, Fujii H. J. Alloy. Compd. 2004; 365: 271-276.

[4] Kojima Y, Kawai Y. Chem. Commun. 2004; 2210-2211.

[5] Liang G, Hout J, Boily S, Van Neste A, Schulz R. J. Alloy. Compd. 1999; 292: $247-252$

[6] Barkhordarian G, Klassen T, Bormann R. J. Alloy. Compd. 2004; 364: 242-246.

[7] Barkhordarian G, Klassen T, Bormann R. Scripta Mater. 2003;49: 213-217.

[8] Jin SA, Shim JH, Cho YW, Yi KW. J. Power Sources. 2007; 172: 859-862.

[9] Borgschutle A, Bösenberg U, Barkhordarian G, Dornheim M, Bormann R. Catalysis Today. 2007; 120: 262-269.

[10] Barkhordarian G, Klassen T, Bormann R. J. Alloy. Compd. 2006; 407: 249-255.

[11] Hanada N, Ichikawa T, Hino S, Fujii H. J. Alloy. Compd. 2006; 420: 46-49.

[12] Hanada N, Hirotoshi E, Ichikawa T, Akiba E, Fujii H. J. Alloy. Compd. 2008; 450: 395-399.

[13] Hanada N, Ichikawa T, Isobe S, Nakagawa T, Tokoyoda K, Honma T, Fujii H, Kojima Y. J. Phys. Chem. C. 2009; 113: 13450-13455. 
[14] Porcu M, Petford-Long AK, Sykes JM. J. Alloy. Compd. 2008; 453: 341-346.

[15] Kissinger HE. Anal. Chem. 1957; 29: 1702-1706.

[16] Friedrichs O, Sánchez-López JC, López-Cartes C, Klassen T. J. Phys. Chem. B. 2006; 110: 7845-7850.

[17] Friedrichs O, Aguey-Zinsou A, Ares Fernández JR, Sánchez-López JC, Justo A, Klassen T, Bormann R, Fernández A. Acta Mater. 2006; 54: 105-110.

[18] Ho SF, Contarini S, Rabalais JW. J. Phys. Chem. 1987; 91: 4779-4788.

\section{Figure captions}

Fig. 1. Profiles of TDS of hydrogen for HM sample and those ball-milled for $0.02 \mathrm{~h}$,

$0.2 \mathrm{~h}, 2 \mathrm{~h}$ and $20 \mathrm{~h}$

Fig. 2. Correlation between $E a$ and ball-milling time for HM sample ( $0 \mathrm{~h})$ and those ball-milled for $0.02 \mathrm{~h}, 0.2 \mathrm{~h}, 2 \mathrm{~h}$ and $20 \mathrm{~h}$

Fig. 3. X-ray diffraction profiles of HM sample and those ball-milled for $0.02 \mathrm{~h}, 0.2 \mathrm{~h}$, $2 \mathrm{~h}$ and $20 \mathrm{~h}$

Fig. 4. TEM micrographs of HM and ball-milled samples: bright field images of HM (a), $0.02 \mathrm{~h}(\mathrm{~b}), 0.2 \mathrm{~h}(\mathrm{c}), 2 \mathrm{~h}(\mathrm{~d}), 20 \mathrm{~h}(\mathrm{e})$ and the selected area diffraction from area A (f) and B (g)

Fig. 5. XPS spectra of HM sample and those ball-milled for 0.02 h, 0.2 h, 2 h, and 20 
$\mathrm{h}$. The insert graph shows the Nb3d peak separation of the sample milled for $0.2 \mathrm{~h}$ 


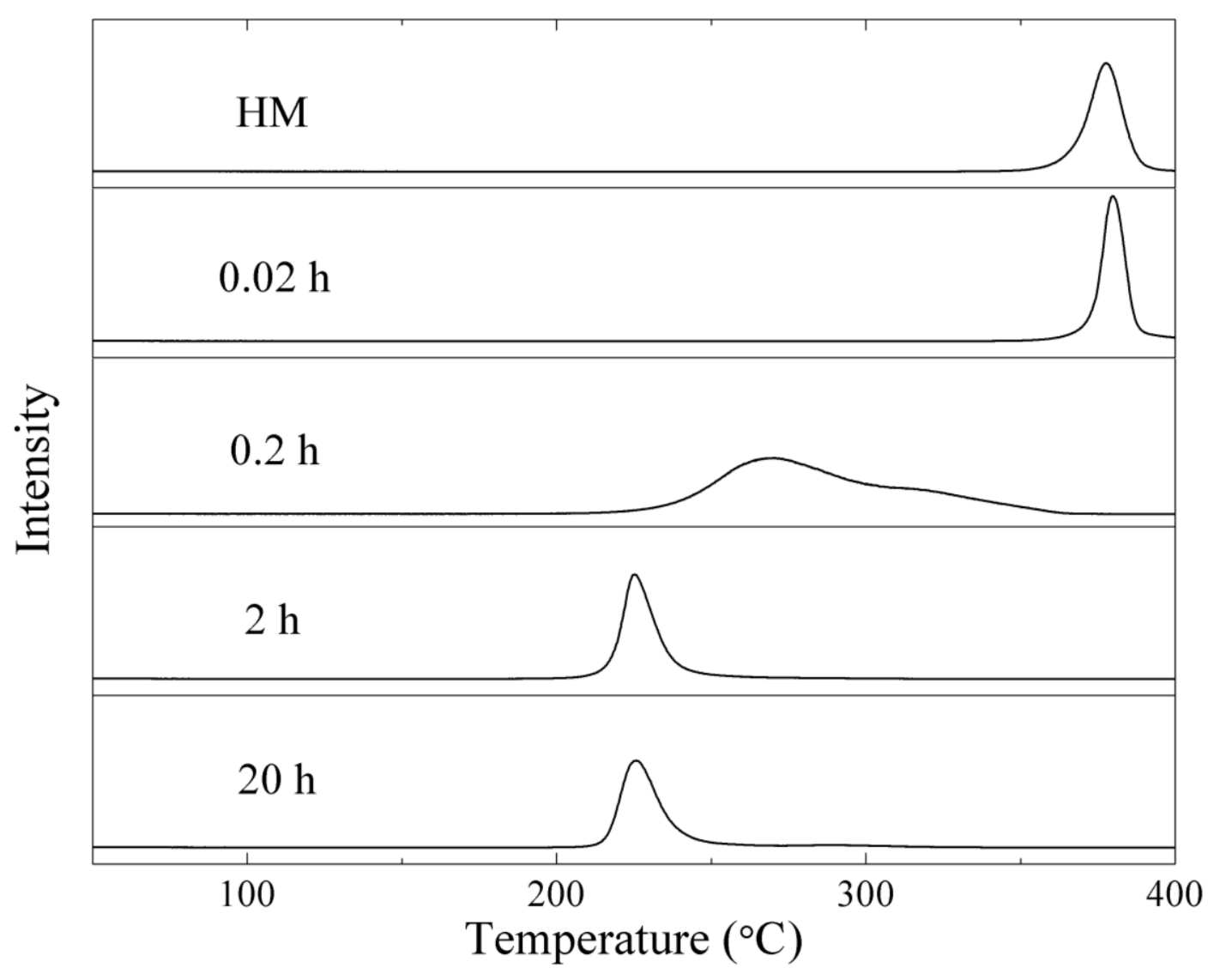

Figure 1 


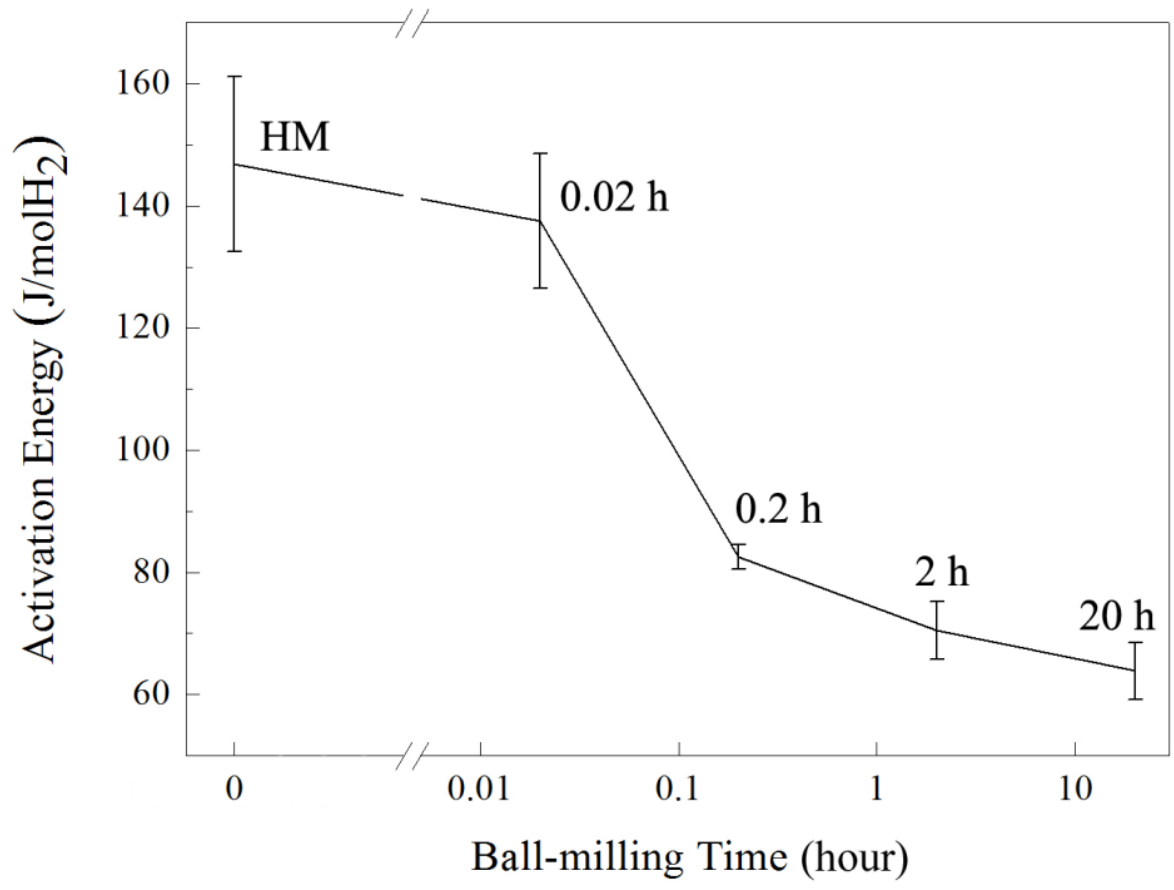

Figure 2 


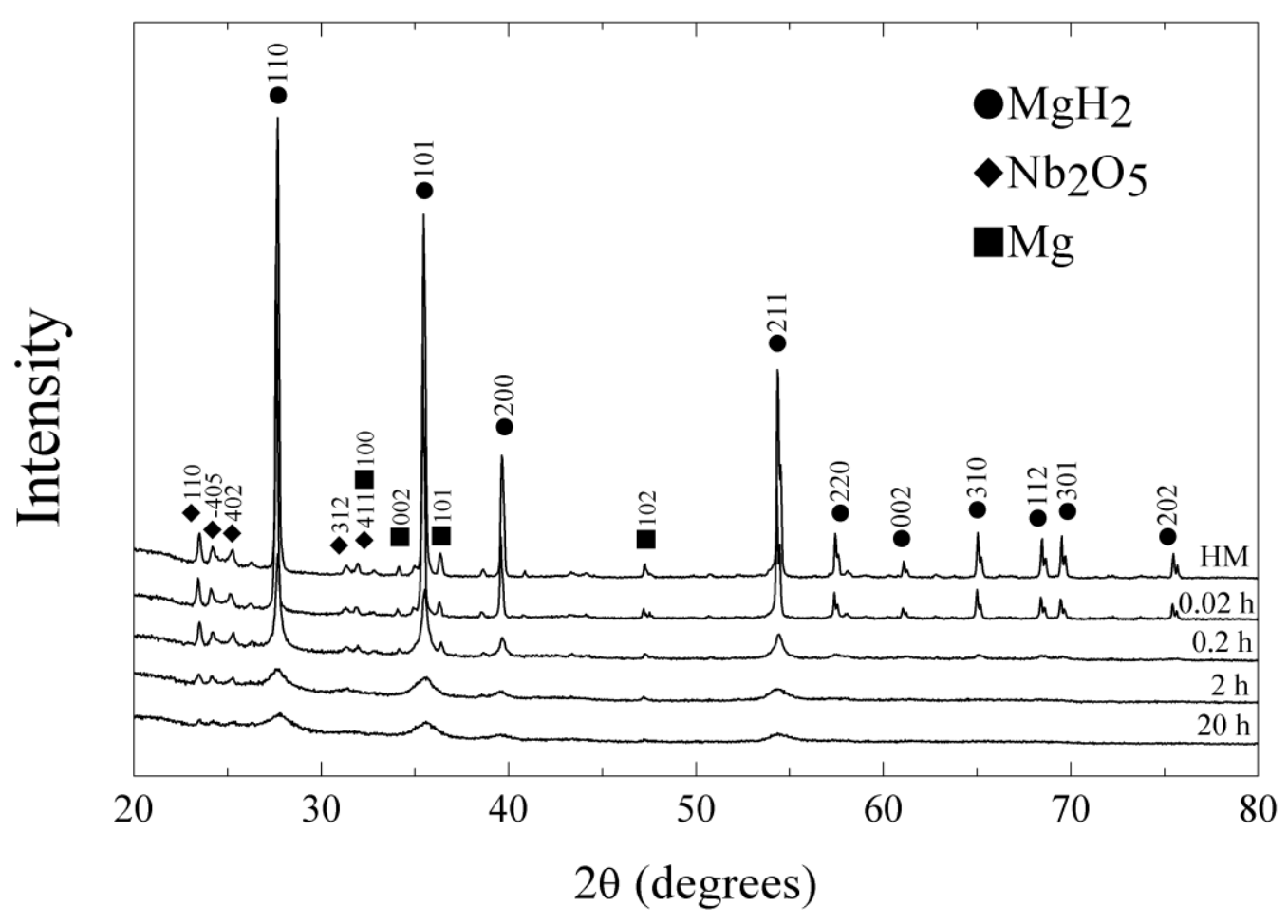

Figure 3 

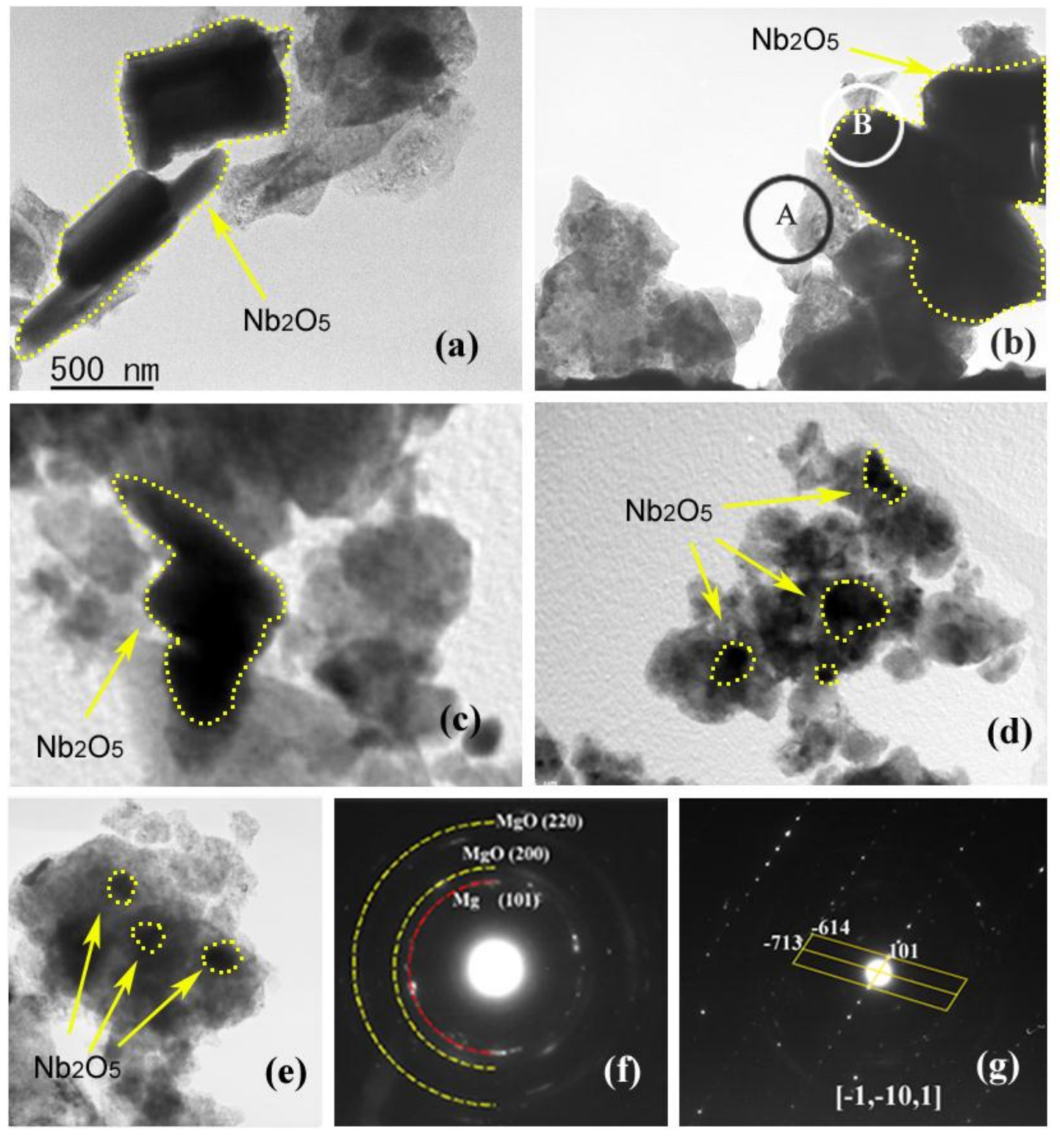

Figure 4 


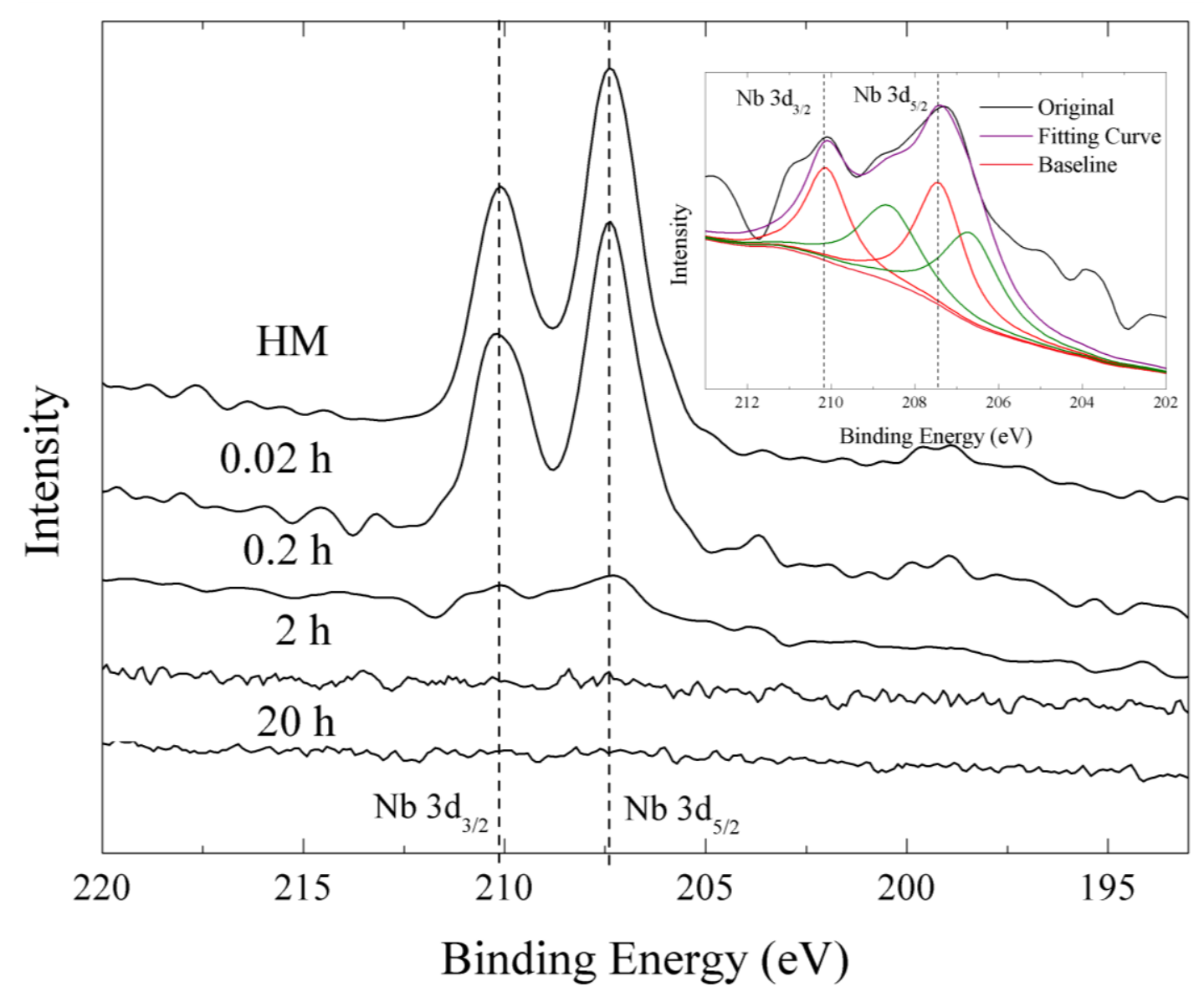

Figure 5 